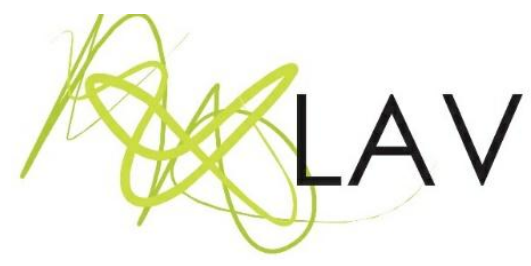

\title{
O processo de escolha dos livros didáticos por professores de Arte ${ }^{1}$ : Mediações (in)imagináveis
}

The process of choosing textbooks by Art Teachers: (un)imaginable mediations

\author{
Mauren Teuber \\ Universidade Estadual do Paraná
}

Guilherme Gabriel Ballande Romanellii

Universidade Federal do Paraná

\section{Resumo}

Esta pesquisa, em andamento, tem como objetivo compreender as dinâmicas relativas ao processo de escolha e uso dos livros didáticos de Arte na Escola Pública. A primeira etapa do estudo, caracterizado como uma pesquisa qualitativa, é um trabalho coletivo e colaborativo na elaboração de um questionário para obter informações relativas ao processo de escolha dos livros de Arte do Programa Nacional de Livro Didático - PNLD 2020 e uso dos livros didáticos de Arte na escola. Realizada junto a um grupo de 32 professores de Arte que atuam na Educação Básica no Estado do Paraná, o resultado aponta para a presença do livro didático em quase todas as escolas dos professores participantes. Reconhece-se a urgência de se tratar desse tema na formação inicial e continuada, em função da pouca tradição que o livro tem na disciplina, e a pequena valorização dessa temática no âmbito da pesquisa acadêmica.

Palavras-chave: Ensino de Arte, Livros didáticos, PNLD.

\begin{abstract}
The main objective of this ongoing research is to understand the dynamics related to the process of choice and use of textbooks by Art teachers in public schools. The first step of this qualitative study is the result of a collective and collaborative effort to design a survey in order to bring information related to the process of choice of Art textbooks, under the National Brazilian Textbook Program, known as PNLD 2020 and their use in schools. Developed with 32 Art teachers from public schools in the state of Paraná (Southern Brazil), the study results show that the textbooks are found in almost all of the teachers' schools. It is also noticeable that there is a demand that textbooks should be studied in the various levels of teachers' formation, and that this topic is still undervalued in academic research.
\end{abstract}

Keywords: Art Education, Textbooks, PNLD.

Enviado em: 19/11/20 - Aprovado em: 20/11/20

\footnotetext{
${ }^{1}$ Gostaríamos de agradecer às professoras Keila Lima Pieralisi, Maria Ravazzani de Almeida, e Sabrina Rosa Cadori que fazem parte do grupo de pesquisa que reúne professores da Rede Estadual de Educação do Paraná, da Universidade do Paraná e da Universidade Federal do Paraná e que contribuem para o projeto de extensão Mediações (in)imagináveis: o livro didático e o ensino da Arte. Essas professoras foram as anfitriãs deste projeto que se desenvolveu nas dependências do Centro Estadual de Capacitação em Artes Guido Viaro (CECAA).
}

Revista Digital do LAV - Santa Maria - vol. 13, n. 3, p. 114 - 137 - set./dez. 2020 ISSN 1983 - 7348 http://dx.doi.org/10.5902/1983734863144 


\section{Introdução}

Os livros didáticos se encontram, atualmente, no centro de umas das mais importantes políticas educacionais do Ministério da Educação, o Programa Nacional do Livro Didático (PNLD) ${ }^{2}$. A disciplina de Arte, que até meados da década de 2015 não figuravam em um programa com estas características (ROMANELLI, 2020), passou a ser contemplada pelo Programa Nacional do Livro Didático para o Ensino Médio (PNLEM) e, mais recentemente, foram incorporadas ao PNLD, política pública de compra e de distribuição de livros existente no Brasil desde 1985.

A incorporação dos livros didáticos em programas como o PNLD contribuiu para que ocorresse um salto quantitativo nas pesquisas educacionais no Brasil. Destaca-se pesquisas realizadas já a partir de 1950 (GARCIA, 2009), embora tenham recebido um impulso apenas a partir da década de 1980, num primeiro momento por meio de um recenseamento da produção escolar e, num segundo, por meio de pesquisas mais exaustivas (CHOPPIN, 2004).

As investigações no conjunto da produção acadêmica sobre as publicações didáticas fornecem, apesar das dificuldades de categorização de elementos, pelo menos quatro linhas de investigação principais, segundo Choppin (2004) e Garcia (2009). A primeira linha integra estudos críticos, históricos e ideológicos sobre o conteúdo dos livros. A segunda se refere a estudos formais, linguísticos e psicopedagógicos sobre a legibilidade e a compreensibilidade dos livros. A terceira diz respeito a estudos sobre as políticas culturais, editoriais e a economia política do livro, materializada nos níveis da produção, da circulação e do consumo. E a quarta linha corresponde às pesquisas sobre os usos do livro didático no espaço escolar.

Tendo como base o estudo de Choppin (2004), essas linhas podem ser condensadas em duas grandes vertentes: i) uma abordagem na qual os livros são tomados como um 'documento histórico' e ii) em estudos focados com aspectos relativos à sua comercialização, circulação, distribuição, avaliação e consumo em dados contextos.

Mesmo que, de forma ampla, os estudos sobre livros e manuais didáticos tenham avançado consideravelmente nos últimos anos (RODRÍGUEZ; GARCIA, 2019), na particularidade do ensino de Arte, a pesquisa sobre os livros didáticos é bem mais recente (TEUBER; SCHLICHTA; RIBEIRO; ROMANELLI, 2016; ROMANELLI, 2019b), em grande parte devido à incorporação recente desse conteúdo curricular no PNLD. Deve-se

\footnotetext{
${ }^{2}$ A partir do Decreto federal n. 9.099, de 18 de julho de 2017 o PNLD passou a ser denominado Programa Nacional do Livro e do Material Didático, mantendo a sigla original (BRASIL, 2017).
} 
O processo de escolha dos livros didáticos por professores de Arte ${ }^{1}$ : Mediações (in)imagináveis

enfatizar também que a Arte se insere no currículo escolar a partir de uma regulamentação que reúne, em um mesmo componente curricular, quatro linguagens: artes visuais, dança, música e teatro, conforme determina a Lei n. 13.278 de 2016 (BRASIL, 2016), razão pela qual, neste texto, o termo Arte sempre fará referência ao componente curricular como um todo (incluindo essas quatro linguagens).

Partindo do pressuposto de que os livros didáticos de Arte devem ser entendidos como recursos para o ensino, e para, além disso, que eles são elementos que materializam concepções sobre o conhecimento a ser ensinado, sobre o processo de ensino e aprendizagem em determinada disciplina e, ainda, as intenções educativas e didáticas dos autores e editoras que o produziram, em determinadas circunstâncias e condições objetivas (TEUBER; GARCIA, 2015), faz-se necessário investigar de que modo essas dimensões se apresentam para os sujeitos que se utilizam desses livros no universo escolar. Assim, neste trabalho, apresentam-se os resultados de uma investigação que objetivou identificar como essas dimensões se fazem presentes na escolha de livros didáticos de Arte por um conjunto de professores que atuam na Educação Básica.

Diante do caráter complexo da disciplina Arte (SCHLICHTA, ROMANELLI e TEUBER, 2018), destaca-se que as pesquisas sobre livros didáticos para o ensino da Arte envolvem categorias de análise que permeiam dimensões muito variadas do processo educacional, desde as instâncias de produção, avaliação, escolha e distribuição até as situações de usos em sala de aula por professores e alunos, razão pela qual optamos por destacar as 'Mediações (in)imagináveis' que caracterizam todo esse processo. A escolha dessa metáfora, enquanto parte do título, também reflete o fato dos livros didáticos ainda serem marcados por uma invisibilidade como objetos de estudo (GARCIA, 2013).

\section{Os livros didáticos de Arte na Educação Brasileira}

Para Choppin (2000), os livros didáticos atuam como um modelo de ensino e são frutos de um conjunto de determinantes sempre subordinados a intenções explícitas ou implícitas, ligados a um determinado contexto histórico. Trata-se de um objeto complexo (BATISTA, 2002), uma vez que está diretamente ligado a práticas culturais dos mais diversos sujeitos escolares (gestores, professores e alunos) e também relacionado a um grande conjunto de elementos extraescolares (legislação educacional, orientações curriculares nacionais, editais de aquisição e distribuição, mercado editorial, entre outros). 
Mesmo gozando de certa hegemonia nos ambientes escolares, o livro didático ainda mantém o status de livro 'menor' (GIMENO-SACRISTÁN, 2012), unicamente relacionado a atividades acadêmicas e 'culturalmente consumível', uma vez que pode ser descartado após cumprir sua função durante o ano escolar ou na preparação de exames.

Por tantas características que determinam a particularidade do livro didático, este pode ser entendido enquanto vasto campo de estudo que permite compreender diversas facetas da escola. É, portanto, diante desse contexto que se justificam estudos sobre os livros didáticos.

Para melhor compreender os livros didáticos de Arte na educação brasileira, é importante fazer uma breve incursão nos diversos rumos que a Arte tomou.

A arte, no currículo escolar, sob a denominação de Educação Artística, tem como marco legal a Lei de Diretrizes e Bases para o ensino de $1^{\circ}$ e $2^{\circ}$ graus, n. 5.692, promulgada em 1971 (BRASIL, 1971), que indicou pela primeira vez a obrigatoriedade da Educação Artística. Desde sua origem, a disciplina contempla a polivalência, já que os primeiros Cursos de Licenciatura, criados na década de 1970, formavam professores habilitados para atuar em todas as áreas artísticas. A polivalência é ainda uma das questões centrais no debate sobre as dificuldades enfrentadas pela disciplina, por pressupor que o professor que trabalha com uma linguagem artística específica deve ter também o domínio dos conhecimentos básicos das diferentes linguagens artísticas.

A partir da Lei de Diretrizes e Bases da Educação Nacional/LDB, n. 9.394/1996 (BRASIL, 1996), instaura-se o termo Ensino da Arte e não mais Educação Artística, terminologia que pressupõe uma mudança epistemológica, teórica e política (BARBOSA, 2003). Uma das alterações que sofreu o texto da LDB, entre outras, destaca-se a redação do $\S 6^{\circ}$ do art. 26 na Lei n. 13.278, nomeando 'as artes visuais, a dança, a música e o teatro' como as linguagens constituintes do componente curricular arte, considerada uma vitória pela Federação de Artes Educadores do Brasil (FAEB) e um importante passo para a efetivação das especificidades da arte no espaço escolar (VASCONCELLOS; STORCK; MOMOLI, 2018).

Na trajetória histórica do ensino da arte no Brasil, o livro didático não tem assumido papel de destaque e é recente a valorização dessa temática no âmbito da pesquisa acadêmica (SCHLICHTA, ROMANELLI e TEUBER, 2018).

Vale destacar um trabalho pioneiro, realizado no âmbito da Associação de Arte Educadores de São Paulo, a AESP, no qual, um grupo de trabalho, formado por Maria 
O processo de escolha dos livros didáticos por professores de Arte ${ }^{1}$ : Mediações (in)imagináveis

Heloísa Ferraz, Maria Christina Rizzi e Idméa Semeghini-Siqueira, elaboraram um questionário sobre materiais e métodos de arte educação e o aplicaram para 150 professores de Educação Artística. Esse material foi publicado, em 1987, com o título Arte-educação: vivência, experienciação ou livro didático?. Entre as várias questões abordadas pelo questionário, merece destaque o item sobre livro didático. De acordo com as autoras, esse item obteve um dos maiores índices de resposta, o que causou surpresa, visto que indagações sobre a importância do ensino de Educação Artística não teve a mesma participação (FERRAZ, SEMEGHINI-SIQUEIRA, 1987).

Dos 150 informantes, 98\% relataram conhecer livros didáticos em arte e discriminaram o título dos livros, sendo que $82,8 \%$ consultam os livros didáticos para a preparação de suas aulas. As pesquisadoras destacam que a maioria dos professores de Educação Artística, na época, consideravam os livros existentes no mercado de má qualidade e salientavam a polivalência na formação e atuação do professor como um dos motivos para a adoção desses livros.

Outro trabalho relevante é a dissertação de Amanda Siqueira Torres Cunha, no Programa de Pós-Graduação em Educação, da Universidade Federal do Paraná (UFPR), que ao tratar do livro didático, em específico da Coleção Educação Artística no contexto da Lei n. 5.692/71, indica a crescente publicação de livros de Educação Artística à época. Segundo Cunha (2015), os primeiros livros escolares da área publicados por empresas privadas ou em regime de coedição foram frutos de demandas originadas pela Lei $n$. 5.692/71. Essas obras eram direcionadas à educação nacional em anos da ditadura civilmilitar, pois a novíssima área de Educação Artística colocava-se como propulsora e em consonância com os interesses de um mercado editorial.

Na década de 1970 e 1980, o material apresentado nos livros didáticos de Arte já não se restringia ao rigor de exercícios de geometria e de aspectos estritamente técnicos, como os anteriores, mas tinham a ênfase em métodos relacionados ao desenho do natural, apontando para uma concepção de desenho mais livre e vinculada às linguagens artísticas ou ao design. Em seu estudo, Cunha (2015) cita materiais desse período marcados pelos novos meios de impressão e ricos em imagens coloridas, bem como destaca um esforço de legitimação da História da Arte no currículo escolar, a partir da veiculação de imagens e de problemas relevantes para a área da estética, ou seja, um movimento de inserção da arte e de seus conteúdos, ainda que pouco esclarecidos pela legislação.

Um terceiro trabalho que merece destaque se refere ao estudo desenvolvido pelo Grupo de Pesquisa em Mediação Cultural do Programa de Pós-Graduação em Educação, 
Arte e História da Cultura da Universidade Presbiteriana Mackenzie, coordenado pela Profa. Dra. Mirian Celeste Martins (2010). O estudo envolve os Cadernos do Aluno material didático de Arte, oferecido para as Escolas Públicas do Estado de São Paulo. Segundo os autores, o vasto material empírico obtido e a complexidade do tema apontam para a necessidade de ampliação da discussão sobre mediação cultural, processos de ensino, materiais educativos e formação de educadores.

Nos últimos anos, é perceptível o aumento de uma produção paradidática direcionada a professores de Arte. Exemplo disso são os materiais educativos, disponibilizados por instituições públicas ou privadas, como museus, centros culturais e bienais, e que necessariamente não têm características de livro. Nesse sentido, destacase a dissertação intitulada Em foco: professores de Artes e suas experiências com os materiais educativos Lá Vai Maria Bem-vindo, professor! artebr, de 2007, de Maria de Lourdes Sousa Fabro (2007), realizada na Universidade Estadual Paulista sob a orientação da Profa. Dra. Mirian Celeste Martins. Este estudo abarca um conjunto de materiais direcionados aos professores de Arte em São Paulo e teve como objetivo ouvir o professor diretamente. Ao final, considera que esses materiais são fundamentais como instrumentos de ação do professor.

Para finalizar essa breve revisão de literatura, cabe destacar duas pesquisas de Mestrado sobre o livro didático de Arte. A primeira intitulada Livros didáticos para o ensino de Arte: diálogos, práticas e (des)caminhos, de Gisele Silva (2009), realizada em 2009, pela Faculdade de Artes Visuais, Universidade Federal de Goiás, em que a autora procurou discutir as formas como o Livro Didático apresenta-se aos alunos e as maneiras com eles o veem e se relacionam com ele. A segunda Livros didáticos de ensino de Arte: avaliação e análise crítica, de Denise Valarini (2016), realizada em 2016, pelo Instituto de Artes da Universidade Estadual de Campinas, em que a autora investigou se os livros didáticos, seus conteúdos e suas propostas práticas são capazes de ampliar o repertório visual e promover uma educação estética de forma efetiva junto aos alunos.

No que se refere ao PNLD, é importante destacar que, desde a primeira metade do século $X X$, existem políticas e programas de incentivo à produção de livros didáticos no Brasil, mas o PNLD existe, com esta denominação, desde 1985. Os primeiros livros didáticos de Arte, do PNLD, fizeram parte do edital de 2015, destinados aos estudantes e professores do Ensino Médio das Escolas Públicas, ou seja, é muito recente sua inclusão no programa.

O programa é fundamentado em um edital público para a inscrição de editoras que pretendem inscrever suas coleções (o conjunto de livros para cada etapa da 
educação, por conteúdo curricular) ao processo de avaliação coordenado pelo Ministério da Educação. Esse processo de seleção já teve diversos formatos, passando pela coordenação de Universidades Federais e atualmente é centralizado na COGEAN (Coordenação Geral de Materiais Didáticos), órgão do MEC.

Ao fim do processo de avaliação, são publicadas as coleções aprovadas e seus resumos, no Guia do Programa Nacional do Livro Didático (PNLD). Com base nesse documento, os professores da Educação Básica escolhem os livros para seus componentes curriculares, que serão utilizados nos quatro anos seguintes (a mudança de 3 para 4 anos foi determinada pelo Decreto n. 9.099 (BRASIL, 2017).

É necessário salientar, no entanto, que nem sempre as escolhas dos professores são contempladas (o que é, em princípio, previsto no edital). Esse detalhe revela a complexidade de um programa com alcance nacional que movimenta anualmente mais de um bilhão de reais (ROMANELLI, 2019a). Também é oportuno citar que o PNLD ampliou as opções de livros de Arte tanto qualitativamente (ROMANELLI, 2019b) quanto quantitativamente: das dez coleções inscritas no edital PNLD 2020, direcionado aos Anos Finais do Ensino Fundamental, sete coleções foram aprovadas.

\section{Procedimentos metodológicos}

Caracterizada como uma pesquisa qualitativa, esta investigação foi realizada junto a um grupo de professores de Arte que atuam na Educação Básica no Estado do Paraná, com o objetivo de compreender a escolha de livros didáticos por professores. Para geração de dados, optou-se pelo Survey de pequeno porte (BABBIE, 2001), de forma a levantar informações que permitiram construir as categorias de análise que subsidiarão a continuidade deste estudo.

Os dados apresentados aqui são resultado de algumas das ações do grupo Mediações (in)imagináveis: o livro didático e o ensino da Arte, um projeto de Extensão interinstitucional, que envolve duas universidades e um centro de capacitação da Secretaria de Educação do Estado do Paraná - o Centro Estadual de Capacitação em Artes Guido Viaro (CECAA), a Universidade Federal do Paraná e a UNESPAR - Curitiba II, por meio da Faculdade de Artes do Paraná (FAP). O objetivo maior desse grupo é o de criar uma ação formativa e um espaço de aproximação para estudantes universitários e professores da Educação Básica, tendo como objeto de estudo o livro didático de arte. 
A primeira etapa da pesquisa se consistiu em um trabalho coletivo e colaborativo na elaboração de um questionário com o intuito de obter informações relativas ao processo de escolha e o uso de livros didáticos de Arte na Escola. Foram enviados questionários, via Google Forms ${ }^{3}$, a professores de Arte da rede de Ensino da Educação Básica do Estado do Paraná, com retorno de trinta e dois questionários preenchidos.

Na sequência, numa segunda fase da pesquisa, optou-se pela realização de entrevistas em Grupos Focais, com base nas pesquisas de Uwe Flick (2009) e Rosaline Barbour (2009). Esse método de entrevista propicia a interação de um grupo específico para a produção de dados; os participantes levam em conta os pontos de vista dos outros para a formulação de suas respostas e também podem tecer comentários sobre suas experiências e a dos outros. Assim, o foco é a discussão do grupo, que proporciona insights que seriam menos acessíveis sem a interação verificada em um grupo. Nesse caso, a informalidade é necessária para que os participantes contribuam abertamente com suas experiências e opiniões. Por outro lado, exige um preparo do moderador para não deixar o grupo na deriva ou sem foco nas questões abordadas.

Durante o período de realização do processo de escolha dos Livros Didáticos Anos Finais do Ensino Fundamental (60 a $9^{\circ}$ ano) para o PNLD 2020, foram realizados dois encontros com grupos distintos de professores de Arte. O primeiro grupo contou com seis participantes: três professoras de uma escola básica; duas professoras do Centro Estadual de Capacitação em Artes Guido Viaro, e a mediadora professora do Ensino Superior. O segundo grupo também contou com seis participantes: dois professores de uma Escola Básica; uma pedagoga; duas alunas do curso de Licenciatura em Artes Visuais, e a mediadora professora do Ensino Superior. Por meio desses encontros, obteve-se gravações em áudio, que foram transcritas posteriormente, e algumas anotações in loco. Outro momento de escuta e coleta de informações sobre a percepção dos professores de Arte em relação ao uso e a escolha dos livros didáticos de Arte se deu em um curso de formação continuada para professores do Estado (Curso Conexão Professor/SEED), no qual alguns participantes do projeto de Extensão estavam presentes.

No entanto, neste artigo, apresenta-se somente os resultados da primeira fase da pesquisa. Para uma breve caracterização dos sujeitos partícipes, aponta-se que a maioria dos 32 professores ministram aulas no Ensino Fundamental, sendo que 27 atuam em

\footnotetext{
${ }^{3}$ A escolha por esse instrumento de levantamento de dados se deu por conta da praticidade de uso e pela abrangência do meio virtual, que permitiria a participação de professores de todo o estado do Paraná. Em função da sua portabilidade e facilidade de acesso, esse meio de produção de dados também se mostrou adequado, ao considerar a sobrecarga de trabalho que caracteriza o cotidiano dos professores da Educação Básica.
}

Revista Digital do LAV - Santa Maria - vol. 13, n. 3, p. 114 - 137 - set./dez. 2020 ISSN 1983 - 7348 http://dx.doi.org/10.5902/1983734863144 
anos finais, 17 no Ensino Médio, 7 nos anos iniciais do Ensino Fundamental e, por fim, 2 na Educação de Jovens e Adultos. Convém comentar que um professor pode atuar em mais de uma modalidade.

\section{Resultados e análises}

A análise das informações obtidas com os instrumentos de pesquisa permitiu observar elementos de aproximação e de afastamento acerca dos aspectos considerados para a escolha dos livros didáticos de Arte pelos professores pesquisados.

Observa-se sobre a área de interesse entre os professores de Arte que vinte deles $(62,5 \%)$ tem maior interesse nas Artes Visuais, sete em Música, três em Teatro, e dois participantes responderam que têm interesse em todas as linguagens. Não houve participantes com interesse específico por Dança. A seguir, o gráfico 1 demonstra esses resultados:

Qual é sua área de maior interesse no ensino da Arte? 32 responses
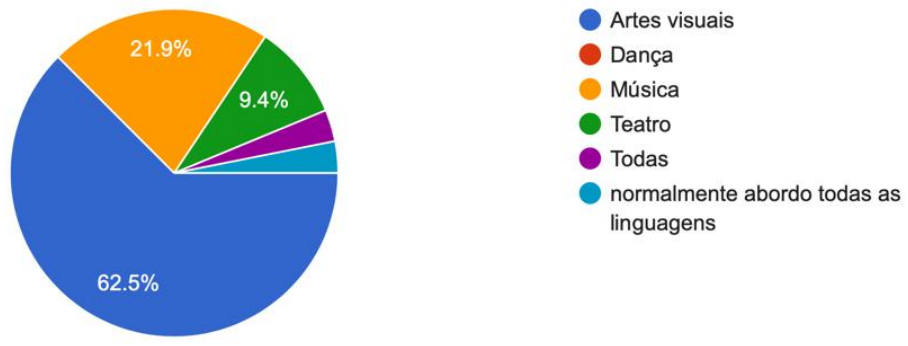

Gráfico 1: Qual é sua área de maior interesse no ensino de Arte? Fonte: os autores (2020)

O maior número de professores ligados às Artes Visuais reflete uma tradição histórica da trajetória do ensino da Arte no Brasil (BARBOSA, 2003). A herança da hegemonia de conteúdos ligados às Artes Visuais existe desde a década de 1970, particularmente a partir da LDB 5692 que instituía a Educação Artística como atividade obrigatória na Educação Básica (BRASIL, 1971).

Das quatro linguagens artísticas abordadas pelo componente curricular Arte (BRASIL, 2016), a dança ainda é a menos contemplada. Isso é resultado do pequeno número de instituições que forma professores licenciados em Dança e também pelo fato 
da dança fazer parte do componente curricular Educação Física, conforme sugerem os PCNs (BRASIL, 1997) e determina a BNCC (BRASIL, 2018).

Em linhas gerais, a maioria das escolas nas quais os participantes atuam como professores já adotaram o livro didático de Arte do PNLD. Nota-se que a grande maioria já utilizou o livro didático em suas aulas de Arte $(84,4 \%)$, conforme o gráfico 2.

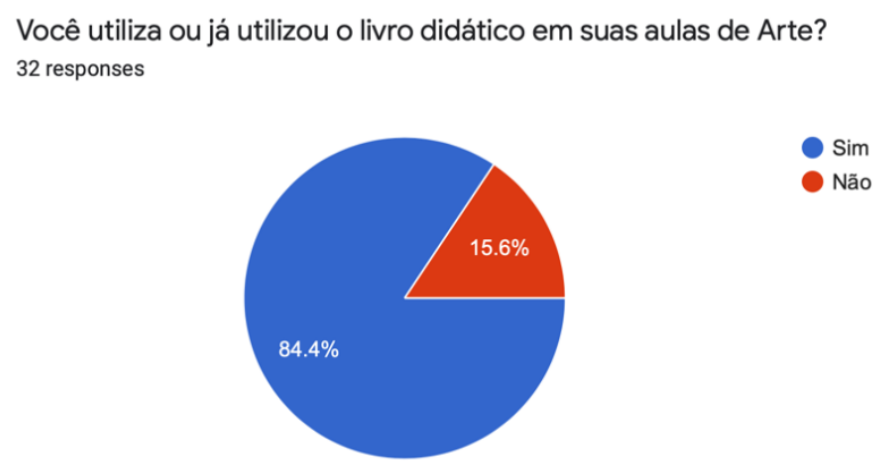

Gráfico 2: Você utiliza ou já utilizou o livro didático em suas aulas de Arte? Fonte: os autores (2020)

A oferta de livros didáticos para o ensino da Arte é relativamente recente, se comparado a outros componentes curriculares. O PNLD oferece livros para Arte apenas desde 2015. O uso de livros didáticos para o ensino de Arte ocorria de forma isolada em algumas escolas, geralmente a partir da demanda dos professores, ou por conta de iniciativa de algumas secretarias de educação.

Muito embora a grande parte dos professores tenha utilizado livros do PNLD (56\%), um número considerável usou o livro didático público de Arte do Estado do Paraná $(25 \%)$ e, em menor quantidade, outros livros didáticos (19\%), conforme o registro do gráfico 3. A prevalência do uso do livro didático público por esses professores é resultado da oferta ampla e gratuita em todo o estado do Paraná desde 2006, ou seja, quase 10 anos antes da primeira oferta de livros de Arte pelo PNLD. Esse livro ainda pode ser consultado e baixado livremente no portal Dia a Dia da Educação (PARANÁ, SEED, 2020). Esse dado demonstra que a familiaridade no uso de um determinado livro didático ainda é um fator importante na sua escolha. Posteriormente, em outra fase da pesquisa, esse fato poderá ser melhor avaliado por meio do grupo focal ou entrevistas. 
Caso afirmativo, você utilizou:

32 responses

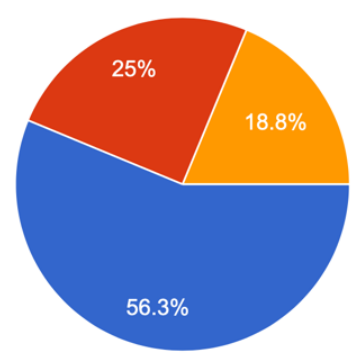

Livro didático do PNLD

Livro didático público do Estado do

Paraná

OUTRO LIVRO DIDÁTICO

Gráfico 3: Escolhas de livros

Fonte: os autores (2020)

Quanto a escolha dos livros, a maioria dos professores participou do processo de escolha $(87,5 \%)$. Abaixo, o gráfico 4 comprova esse dado:

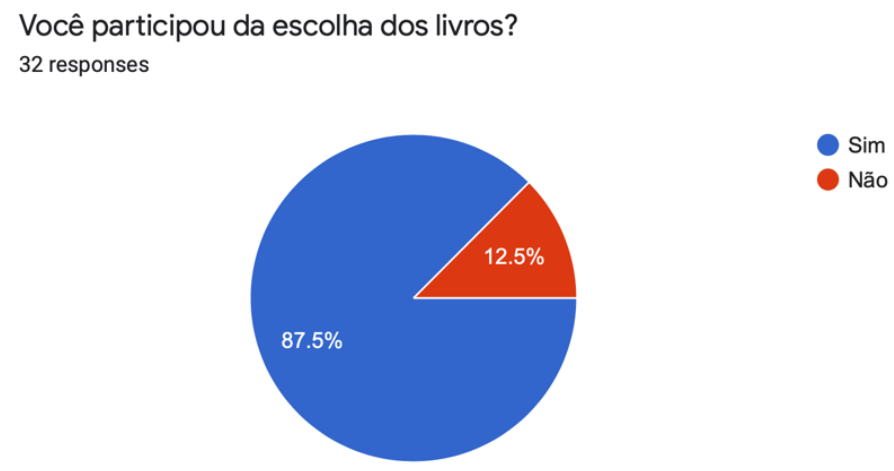

Gráfico 4: Você participou da escolha dos livros? Fonte: os autores (2020)

Deve-se salientar que o elevado número de professores que participou da seleção dos livros PNLD 2020 talvez não reflita a maior parte dos professores de Arte no Estado. Isso ocorre, porque grande parte deles tem alguma ligação com os projetos de formação continuada, oferecidos pelo CECAA Guido Viaro e, tradicionalmente, estão mais mobilizados com as discussões sobre o ensino de Arte, incluindo os processos de escolha dos livros didáticos do PNLD. Esse dado talvez não reflita a maioria dos professores de Arte do Estado do Paraná, já que o período de escolha dos livros é 
extremamente reduzido ${ }^{4}$ e coincide com as várias atividades que esses professores já assumem.

Para a maioria, o processo de escolha foi coletivo (75\%) e, para a minoria, individual (25\%). Tal informação destaca a importância do coletivo de professores de Arte na escolha do livro didático mais adequado a sua realidade, incluindo fatores como alinhamento ao Projeto Político Pedagógico (PPP), da unidade educacional, estruturas das obras e encaminhamentos metodológicos, entre outros fatores. Destaca-se que, em função do porte da escola, há, em alguns casos, apenas um professor de Arte, razão pela qual o trabalho de escolha não pode ser feito de forma coletiva.

Sobre o período disponibilizado aos professores para escolha do livro didático para os anos finais do Ensino Fundamental no âmbito do (PNLD) 2020, prazo definido pelo Fundo Nacional de Desenvolvimento da Educação (FNDE), destaca-se que o modelo de escolha adotado pela Secretaria de Estado da Educação e do Esporte (SEED) foi o de escolher um material único para toda a rede Estadual de Ensino. Dessa forma, os livros didáticos, com maior número de indicações por parte dos professores, são os utilizados em todas as instituições de ensino da rede em 2020. Essa mudança de modelo é justificada, por três aspectos, segundo a SEED: 1) aos estudantes quando precisarem mudar de escola não sofrerão prejuízos na aprendizagem por iniciarem em uma escola que está trabalhando, em sala de aula, conteúdos diferentes daqueles que eram abordados em sua escola anterior; 2) aos professores, na facilidade do planejamento de suas aulas quando atuarem em duas ou mais escolas; 3 ) à rede, trazendo uma melhoria significativa na logística de distribuição de livros 5 .

Com relação ao tempo de escolha, a maioria dos docentes teve mais de duas semanas $(60,7 \%)$, uma parcela menor teve duas semanas $(18 \%)$, um número expressivo uma única semana $(10,7 \%)$, um dia $(3,5 \%)$, e algumas horas $(7,1 \%)$, conforme o gráfico 5 .

\footnotetext{
${ }^{4}$ Em 2019, segundo o Site da Secretaria de Educação e do Esporte do Estado do Paraná (SEED), o prazo para escolha dos livros do PNLD 2020 foi de 4 a 16 de setembro. Disponível em: <http://www.educacao.pr.gov.br/Noticia/FNDE-inicia-periodo-para-escolha-PNLD-2020>.

${ }^{5}$ Acesse: http://www.educacao.pr.gov.br/Noticia/FNDE-inicia-periodo-para-escolha-PNLD-2020.
} 
Quanto tempo você teve para realizar a escolha dos livros? 28 responses

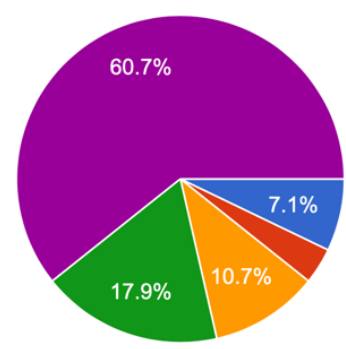

Gráfico 5: Quanto tempo você teve para realizar a escolha dos livros? Fonte: os autores (2020)

Sobre o Guia do Livro Didático6, boa parte dos professores afirmam terem o consultado antes da escolha dos livros (76,7\%). Abaixo, o gráfico 6 demonstra esses resultados:

Caso afirmativo, você consultou o Guia do Livro Didático antes da escolha dos livros? 30 responses

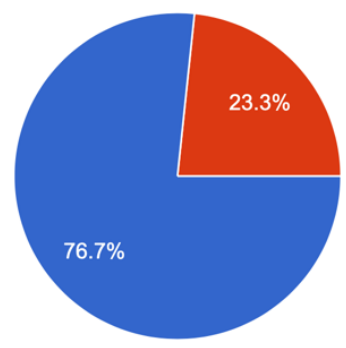

$$
\text { Nim }
$$

Gráfico 6: Você consultou o Guia do Livro Didático antes da escolha dos livros? Fonte: os autores (2020)

Entretanto, metade dos professores (50\%) considera que o Guia ajudou e metade que não ajudou na escolha (50\%). Esses dados estão contidos no gráfico a seguir:

${ }^{6}$ O Guia do Livro Didático contém informações das coleções didáticas aprovadas no PNLD. É lançado a cada edição do PNLD e apresenta as características gerais da obra, os propósitos, os referenciais teóricometodológicos, os conceitos centrais, a abordagem didático-pedagógica e a organização do Manual do Professor e do Manual do Professor Digital. O Guia tem como objetivo subsidiar os critérios de escolha dos professores.

Revista Digital do LAV - Santa Maria - vol. 13, n. 3, p. 114 - 137 - set./dez. 2020 ISSN 1983 - 7348 http://dx.doi.org/10.5902/1983734863144 
Caso afirmativo, o Guia do Livro Didático te ajudou na escolha? 26 responses

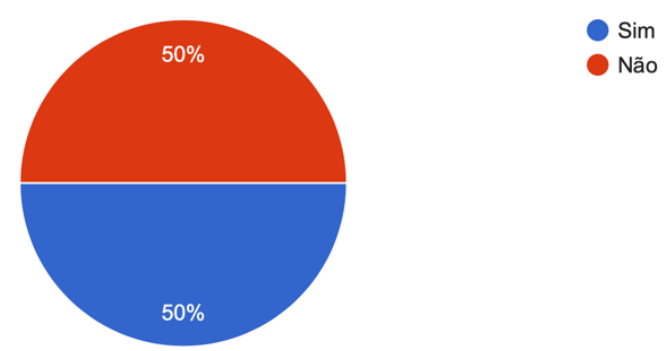

Gráfico 7: O guia do Livro Didático te ajudou na escola? Fonte: os autores (2020)

Dentre as várias funções do Guia do Livro Didático, destaca-se a de apresentar e resenhar cada obra que poderá ser escolhida pelos professores. Em função do número de livros para cada obra (um para cada ano dos Anos Finais do Ensino Fundamental, ou seja, quatro livros), as resenhas são extensas. É plausível pensar que, em função do número de 132 páginas, tenha sido desafiador para o professor ler a totalidade do documento e alinhar os processos de escolha às demandas da comunidade escolar em que atua (BRASIL, 2019).

Sobre os critérios utilizados para a escolha, a opção mais votada da listagem apresentada foi a estruturação do conteúdo $(57,1 \%)$; em segundo lugar, dois critérios receberam o mesmo número de votos, quais sejam: a convergência dos conteúdos com as diretrizes curriculares estaduais $(53,6 \%)$ e a abordagem metodológica $(53,6 \%)$; em terceiro, a opinião de seus colegas de área (professores colegas, grupos de discussão, redes sociais, grupos de estudo, etc.) (39,3\%); em quarto, a qualidade gráfica $(32,1 \%)$; em quinto, a experiência anterior com o livro $(28,6 \%)$; e, em sexto, a adaptação às orientações de trabalho da SEED (sincronia com o registro online, por exemplo) $(17,9 \%)$.

Nota-se, a partir do dado acima, que um alinhamento às diretrizes curriculares tem um peso importante no processo de escolha do livro. Aliás, esse é o primeiro critério apontado pela SEED como requisito do que um bom livro deve ter, ou seja, é necessário que a obra possua uma organização de conteúdos próxima a do Referencial Curricular do Paraná.

Sobre experiências anteriores com o livro didático de Arte, os professores afirmaram que quase a totalidade das escolas receberam o livro solicitado $(84,4 \%)$, 
mesmo que somente em parte chegaram em uma quantidade suficiente para todos os alunos $(65,4 \%)$. A maioria dos professores afirma que os livros estão sendo utilizados este ano $(78,1 \%)$, conforme o gráfico 8 .

\section{Os livros estão sendo utilizados este ano?} 32 responses

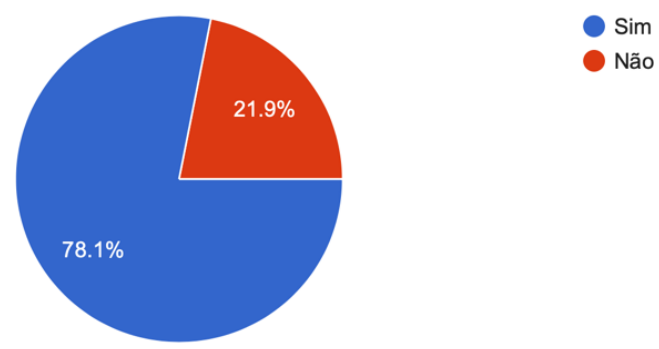

Gráfico 8: Quais livros estão sendo utilizados este ano? Fonte: os autores (2020)

Destaca-se que esta pergunta diz respeito aos livros que já estão na escola e não aos livros que estão sendo escolhidos. Posteriormente, ao aprofundar a pergunta (ver Gráfico 13), fica evidente a complexidade sobre o uso e as funções que o livro pode assumir no ambiente escolar.

Sobre quem é a pessoa responsável pela recepção dos livros na Escola, os professores assim responderam: Bibliotecário/a (43,7\%); Pedagogo/a (12,5\%); Agente educacional (9,3\%); não tem (9,3\%); Professor/a afastado/a de sala de aula $(6,3 \%)$; Secretaria $(6,3 \%)$; não souberam dizer $(6,3 \%)$; Coordenador/a (3,15\%); Direção $(3,15 \%)$.

Levando-se em conta que o PNLD é um programa que pretende levar o livro didático a cada estudante brasileiro, nota-se que ainda há desafios consideráveis no processo de distribuição. A fim de subsidiar essa discussão, são necessárias novas pesquisas que percorram não apenas o Brasil como um todo, mas também as particularidades regionais.

Sobre o local onde os livros ficam armazenados, os professores afirmam que ficam com os alunos (50\%); na Biblioteca da escola (46,9\%); em uma sala especial $(28,1 \%)$; na sala de aula $(21,9 \%)$. O gráfico abaixo mostra essas informações: 
Onde os livros ficam armazenados? (você poderá marcar mais de uma opção) 32 responses

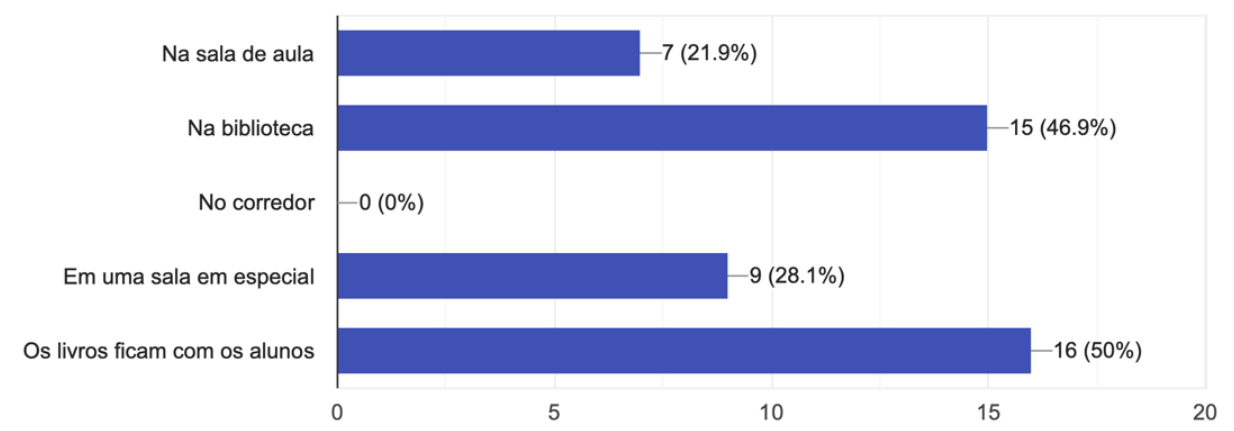

Gráfico 9: Onde os livros ficam armazenados? Fonte: os autores (2020)

Seriam necessárias pesquisas para compreender melhor o papel que o livro didático de arte assume na formação dos alunos. Algumas perguntas, por exemplo, que decorrem desse levantamento são: i) o fato de muitos livros ficarem na escola não é um desafio para a formação?; ii) não seria melhor todos os alunos levarem os livros para casa?; iii) por outro lado, seria inviável carregar quilos de livros todos os dias para a Escola?

Questionados sobre receber livros novos a cada três anos, a grande maioria afirma ser uma vantagem $(81,3 \%)$ e o restante $(18,8 \%)$ afirma ser uma desvantagem (Gráfico 10).

Na sua opinião, receber novos livros a cada três anos: 32 responses

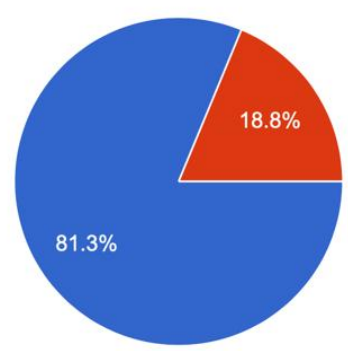

É uma vantagem

É uma desvantagem

Gráfico 10: Receber novos livros a cada três anos é vantajoso ou não? Fonte: os autores (2020) 
O processo de escolha dos livros didáticos por professores de Arte ${ }^{1}$ : Mediações (in)imagináveis

Esses dados merecem um aprofundamento para se compreender a razão de defender um, ou outro ponto de vista. Em primeiro lugar, deve-se refletir para quem a eventual mudança de livros seria vantagem ou desvantagem. Para o professor ou para o aluno? Estamos inclinados a considerar o primeiro caso, já que é sempre o professor que deverá passar por um período de adaptação e estudo, caso o livro com o qual trabalha seja substituído por outro.

Em relação a alguns elementos do livro didático do PNLD, os professores avaliaram (gráfico 11 e 12):

- linguagem: 3 muito bom; 14 bom; 13 regular; 2 ruim;

- temas apresentados: 2 muito bom; 11 bom; 14 regular; 5 ruim;

- sugestão de atividades: 2 muito bom; 9 bom; 12 regular; 8 ruim; 1 muito ruim;

- imagens: 5 muito bom; 13 bom; 10 regular; 4 ruim;

- organização dos conteúdos: 1 muito bom; 6 bom; 19 regular; 2 ruim;

- metodologia: 1 muito bom; 8 bom; 17 regular; 4 ruim; 2 muito ruim;

- indicação de referências e links: 5 muito bom; 15 bom; 10 regular; 2 ruim;

- integração com outras disciplinas: 3 muito bom; 12 bom; 10 regular; 5 ruim; 2 muito ruim;

- orientação aos professores: 3 muito bom; 14 bom; 13 regular; 1 ruim; 1 muito ruim.

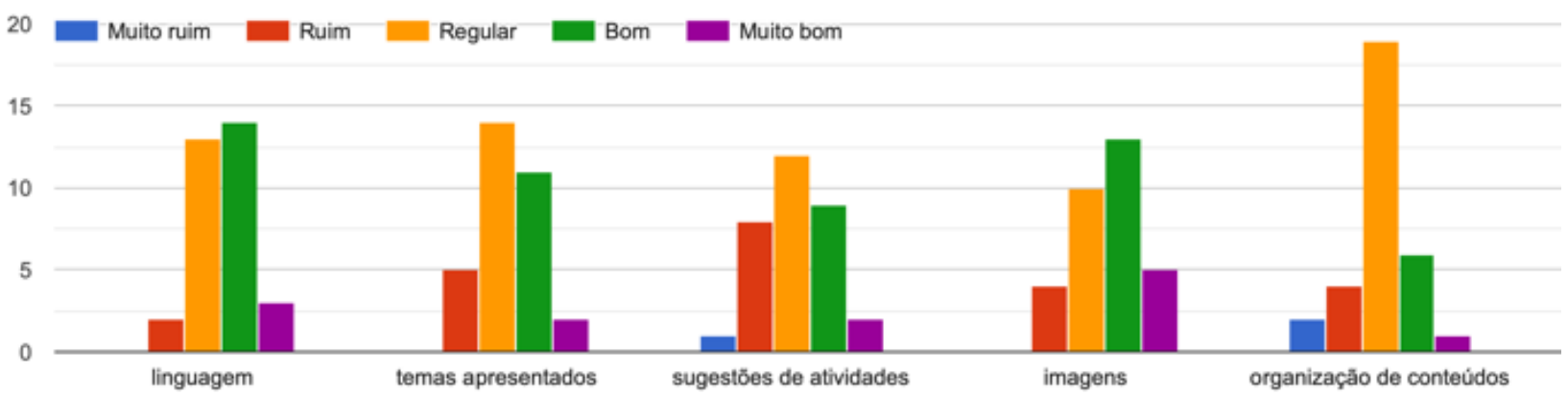

Gráfico 11: Avaliação dos elementos dos livros a partir de conceitos Fonte: os autores (2020) 


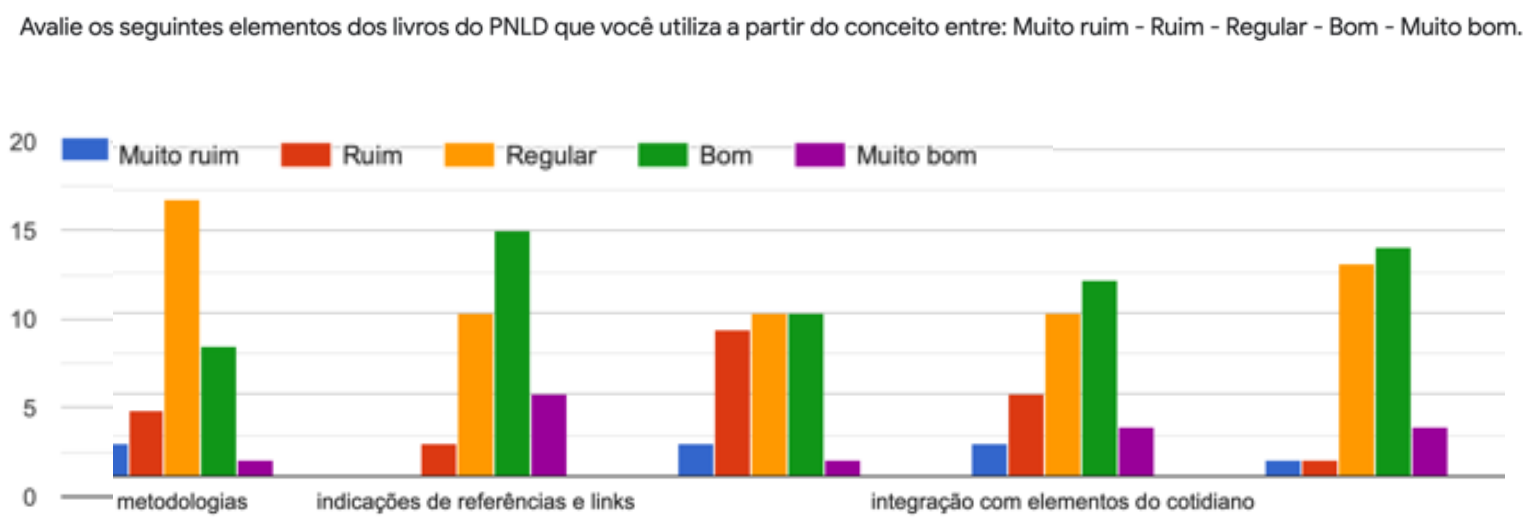

Gráfico 12: Avaliação de outros elementos dos livros a partir de conceitos Fonte: os autores (2020)

Observando-se os resultados presentes nos gráficos acima, é possível perceber que os livros de modo geral são considerados regulares pelos professores.

Sobre o uso mais específico do livro didático, a minoria dos professores afirma usar os livros em toda aula (6,3\%); a maioria dos professores utiliza em algumas aulas $(59,4 \%)$; e parte significativa dos professores utiliza raramente os livros $(34,4 \%)$, conforme o gráfico 13 .

\footnotetext{
Você utiliza o livro

32 responses
}

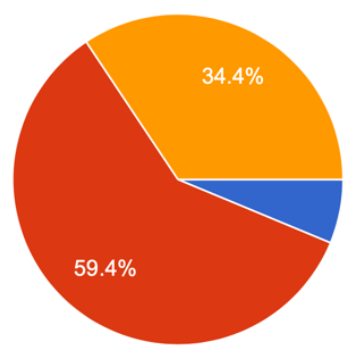

Gráfico 13: Quando você utiliza o livro didático? Fonte: os autores (2020)

A utilização em parte do livro se dá para a maioria dos professores (62,5\%). Em seguida, a maior porcentagem se refere àqueles que usam, mas não seguem a sequência do livro (25\%). Depois, àqueles que seguem a sequência e utilizam todas as 
páginas $(9,4 \%)$. Por fim, àqueles que seguem a sequência, mas excluem algumas páginas (3,1\%). O gráfico 14 , a seguir, representa esses dados:

A utilização do livro é feita

32 responses

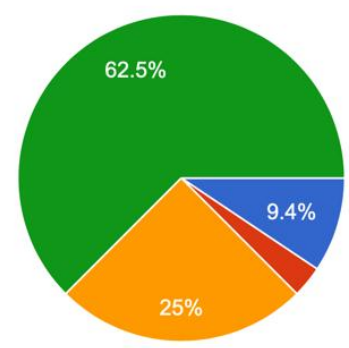

Seguindo a sequência do livro e utilizando todas as páginas

Seguindo a sequência do livro e excluindo algumas páginas

Não seguindo a sequência do livro

Selecionando apenas algumas partes

do livro

Gráfico 14: Como você utiliza o livro didático?

Fonte: os autores (2020)

Os dados sobre os usos dos livros revelam uma particularidade no ensino da Arte, reconhecendo que, no universo pesquisado, o livro didático não pode ser tomado enquanto 'currículo editado', com base no termo cunhado por Antonio Viñao Frago (2000). Nesse caso particular, os livros são um apoio para os professores, o que talvez reflita o fato de serem muito recentes em suas práticas docentes.

Sobre a função do livro (gráfico 15), a maioria o utiliza para preparação de aulas (pesquisas) $(37,5 \%)$; outras funções não descritas $(31,3 \%)$; propostas de atividades $(21,9 \%)$ e para condução da aula $(9,4 \%)$.

Para você, a principal função do livro é:

32 responses

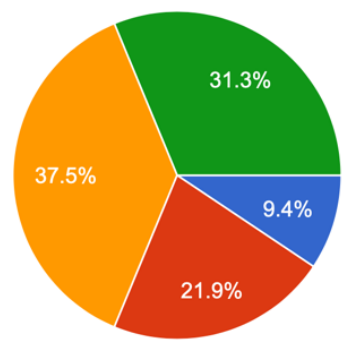

A condução das aulas

Proposta de atividades práticas

A preparação de aulas (pesquisa)

Outras funções: quais?

Gráfico 15: Qual a principal função do livro didático?

Fonte: os autores (2020) 
Conforme Choppin (2000) e Batista (2002), o livro didático é um objeto complexo que pode assumir muitas funções no ambiente escolar. O PNLD prevê explicitamente que uma dessas funções seja a formação do professor, além do papel já evidente que ocupa na formação dos alunos. Essa posição oficial que o livro didático assume justifica a necessidade de novas pesquisas que procurem identificar como esse duplo papel formativo ocorre.

Do total de 32 professores participantes, 20 se dispuseram a continuar a enquete, indicando assim um interesse expressivo de $65 \%$ dos partícipes em continuar com estudos sobre o tema.

\section{Considerações finais}

Em resumo, a análise dos resultados da investigação permitiu perceber que a escolha dos livros didáticos de Arte pelos professores participantes ocorre, na maioria dos casos, de modo participativo, coletivo e com a consulta ao Guia do Livro Didático antes do processo de seleção.

Inicialmente, chama a atenção o fato do livro didático de arte estar presente em quase a totalidade das Escolas Públicas em que esses professores atuam. Ressalta-se que o PNLD somente em 2009 completou a distribuição gratuita de livros nas Escolas Públicas para os componentes tradicionais curriculares, e que, a partir de 2015, a disciplina de Arte passou a fazer parte do programa. Desse modo, muitos dos estudantes de Licenciatura, na última década, "formaram-se professores sem ter passado pela experiência de ter os livros como material didático ou recurso para o ensino e aprendizagem, seja exercendo uma função de suporte dos conteúdos, apoio às atividades ou guia das aulas" (GARCIA, 2013, p. 85). Isso não é diferente para estudantes de Licenciatura em Cursos de Artes Visuais, Dança, Teatro ou Música. É preciso reconhecer que o livro didático é um tema ausente na formação inicial de professores de Arte, basta lembrar a pouca tradição que o livro tem na disciplina e, além disso, é pequena a valorização desta temática no âmbito da pesquisa acadêmica.

O segundo ponto que chama a atenção diz respeito à continuidade do uso do livro didático público de Arte do Estado do Paraná para o Ensino Médio, publicado e distribuído pela Secretaria de Estado da Educação do Paraná para professores e alunos, nos anos de 2005 e 2006. Salta aos olhos que um quarto dos professores continua utilizando esse livro. 
Aponta-se que os livros solicitados estão na maioria das escolas, muito embora ainda que não cheguem a uma quantidade suficiente para todos os alunos. Por outro lado, por este estudo, é possível afirmar, mesmo que de forma indiciária, que os professores utilizam os livros. Entretanto, a grande maioria (94\%) faz uso em algumas aulas ou raramente. Além disso, o uso do livro didático em todas as aulas é mínimo não chegando a $7 \%$-, o que pode ser um forte indicativo de que os livros são apropriados de modo esporádico e de maneira diversa, em especial, para a preparação de aulas. Constata-se também que os professores não seguem a sequência do livro, tampouco utilizam todas as páginas, ou seja, a maioria dos professores usa somente algumas partes do livro. Este último elemento pode sugerir uma interpretação propositiva, levando-se em conta a autonomia do trabalho docente.

Entre outros elementos apontados na análise dos livros, destaca-se que os livros são regulares nas avaliações pelos professores, considerando-se, além dos elementos examinados, a falta de abordagens uniformes das quatro linguagens; a impossibilidade de realizar as atividades em salas de aula com 40 a 45 alunos; a falta da cronologia no ensino da história da arte; e a falta de assuntos que se relacionem a cultura local.

De forma geral, as respostas obtidas na primeira etapa da pesquisa confirmaram a possibilidade de utilização do questionário, indicando a necessidade de novas fases de investigação, o que levou ao uso da entrevista e grupos focais. Justifica-se também, a partir dos resultados obtidos, a relevância de centrar as análises para explorar questões relacionadas à função dos livros didáticos para os professores de arte. Este aprofundamento investigativo possibilitaria verificar e discutir de que forma os livros auxiliam professores na produção de suas aulas, já que, como apontado de modo bastante controverso, a maioria faz uso esporadicamente. Essas questões nortearão a segunda fase da investigação e a continuidade deste trabalho.

Por fim, vislumbra-se aqui a riqueza da pesquisa sobre livros didáticos de Arte no contexto educacional brasileiro, que certamente permite diversas mediações (in)imagináveis.

\section{Referências}

BABBIE, E. Métodos de Pesquisas de Survey. Belo Horizonte: Editora UFMG, 2001.

BARBOSA, A. M. (Org). Inquietações e mudanças no ensino da arte. 2 ed. São Paulo: Cortez, 2003. 
BARBOUR, R. Grupos focais. Porto Alegre: Artmed, 2009.

BATISTA, A. Um objeto variável e instável: textos, impressos e livros didáticos. In: ABREU, M. (Org.). Leitura, história e história da leitura. Campinas: Mercado de letras ALB, São Paulo: Fapesp, 2002.

BRASIL. Ministério da Educação e Cultura. Lei n. 5.692, de 11 de agosto de 1971. Fixa diretrizes e bases para o ensino de $1^{\circ}$ e $2^{\circ}$ graus, e dá outras providências. Diário Oficial da República Federativa do Brasil, Brasília, DF, 12 ago. 1971.

BRASIL, Secretaria de Educação Fundamental. Parâmetros curriculares nacionais: Educação física /Secretaria de Educação Fundamental. - Brasília: MEC/SEF, 1997.

BRASIL. Lei n. 9.394/1996 - Lei de Diretrizes e Bases da Educação Brasileira. Disponível em: <http://www.planalto.gov.br/ccivil_03/LEIS/L9394.htm> Acesso em: 31 maio 2018.

BRASIL. Lei n. 13.278, 2 de maio de 2016. Disponível em: <http://www.planalto.gov.br/ccivil_03/_Ato 2015-2018/2016/Lei/L13278.htm>. Acesso em: 31 maio 2018.

BRASIL. Decreto n. 9.099, de 18 de Julho de 2017 - Dispõe sobre o Programa Nacional do Livro e do Material Didático. Disponível em: <https://www2.camara.leg.br/legin/fed/decret/2017/decreto-9099-18-julho-2017785224-publicacaooriginal-153392-pe.html> Acesso em: 19 nov. 2020.

BRASIL. Ministério da Educação. Base Nacional Comum Curricular. Brasília, 2018.

BRASIL. Ministério da Educação. PNLD 2020: arte - guia de livros didáticos/ Ministério da Educação - Secretaria de Educação Básica - Fundo Nacional de Desenvolvimento da Educação. Brasília, DF: Ministério da Educação, Secretaria de Educação Básica, 2019.

CHOPPIN, A. Pasado y presente de los manuales escolares. In: La cultura escolar de Europa. Madrid: Biblioteca Nueva, 2000.

CHOPPIN, A. História dos livros e das edições didáticas: sobre o estado da arte. Educação e Pesquisa, São Paulo, v. 30, n. 3, p. 549-566, 2004.

CUNHA, A. S. T. A coleção Educação Artística no contexto da Lei no 5.692/71: entre as prescrições legais e as práticas editoriais. 2015. 271 p. Dissertação (Mestrado em Educação) - Universidade Federal do Paraná, Setor de Educação, Programa de PósGraduação em Educação. Curitiba, 2015.

FABRO, M. de L. S. Em foco: professores de Artes e suas experiências com os materiais educativos - Lá vai Maria, Bem-vindo, professor! e arte br. 2007. 204 p. Dissertação (Mestrado em Pós-graduação em Artes Visuais) - Instituto de Artes/Unesp, 2007.

FERRAZ, M.; SEMEGHINI-SIQUEIRA, I. Arte-educação: vivência, experienciação ou livro didático? [S.I: s.n.], 1987.

FLICK, U. Introdução à pesquisa qualitativa. Porto Alegre: Artmed, 2009.

GARCIA, T. Relações de professores e alunos com os livros didáticos de Física. In: SIMPÓSIO NACIONAL DE ENSINO DE FÍSICA, XVIII, 2009, Vitória. Atas... São Paulo: SBF, 2009. p. 1-10. 
GARCIA, T. M. F. B. Os livros didáticos na sala de aula. In: GARCIA, T. M. F. B.; SCHMIDT, M. A.; VALLS, R. (Org.). Didática, História e manuais escolares: contextos ibero-americanos. 1. ed. Ijuí (RS): Editora Unijuí, 2013. pp. 69-102.

GIMENO-SACRISTÁN, J. Grandeza y miseria del libro de texto. Santiago de Compostela: IARTEM, 2012.

LIVRO DIDÁTICO. Dia a dia Educação, 2020. Disponível em: <http://www. educadores.diaadia.pr.gov.br/modules/conteudo/conteudo.php?conteudo $=6>$. Acesso em: 18 nov. 2020.

MARTINS, M. C. Arte no caderno do aluno para escolas públicas do estado de São Paulo: fendas de acesso para arte e cultura? In: $19^{\circ}$ Encontro da Associação Nacional de Pesquisadores em Artes Plásticas "Entre Territórios", 2010, Bahia. Anais... Bahia: Cachoeira, 2010. P 2379 -2393. Disponível em: <http://www.anpap.org.br/anais/2010/pdf/ceav/mirian_celeste_ferreira_dias_martins.pd f>. Acesso em: 18 nov. 2020.

RODRÍGUEZ, J.; GARCIA, T. IARTEM and its international growth and development in recent years (2010-2018). In RODRÍGUEZ, J.; GARCIA, T. and BRUILLARD, E. (Ed.) IARTEM 2016-2016, 25 years developing textbook and educational media research. Santiago de Compostela: IARTEM, 2019a.

ROMANELLI, G. Research on music textbooks in Brazil. In Rodriguez, J.; Garcia, T. and Bruillard, E. (Ed.) IARTEM 2016-2016, 25 years developing textbook and educational media research. Santiago de Compostela: IARTEM, 2019a.

ROMANELLI, G. Entre o digital e o impresso: perspectivas nos manuais e mídias para o ensino de música no Brasil. Revista Latinoamericana de Tecnología Educativa, v. 18, n. 2, dez. 2019b. Disponível em: <http://dx.medra.org/10.17398/1695288X.18.2.57>. Acesso em: 18 nov. 2020.

ROMANELLI, G. Didactic materials for Music Education: A Brazilian panorama and some challenges. In: Vicente Álvarez, R. M., Gillanders, C., Rodríguez Rodríguez, J., Romanelli, G. \& Pitt, J. (Org.) Music education and didactic materials. Santiago de Compostela: Grupo STELLAE/IARTEM, 2020.

SCHLICHTA, C.; ROMANELLI, G.; TEUBER, M. Livros didáticos para o ensino da arte: não peça a eles o que eles não podem te dar. Revista GEARTE, Porto Alegre, v. 5, n. 2, p. 312-325, maio/ago. 2018. Disponível em: <http://dx.doi.org/10.22456/23579854.83949>. Acesso em: 18 nov. 2020.

SILVA, G. C. F. da. Livros didáticos para o ensino de arte [manuscrito]: diálogos, práticas e (des)caminhos. 2009. 119 p. Dissertação (Mestrado) - Universidade Federal de Goiás, Faculdade de Artes Visuais, 2009.

TEUBER, M.; GARCIA, T. Relações entre ensino e pesquisa: questões para a formação do professor de arte. In: EDUCERE - Congresso Nacional de Educação, 12, 2015, Curitiba. Anais... Curitiba, 2015.

TEUBER, M.; SCHLICHTA, C.; RIBEIRO, P.; ROMANELLI, G. A seleção dos livros didáticos de arte PNLD: Análise e uso em sala de aula. In: Balance y análisis de la investigación sobre el livro de texto escolar y los médios digitales. Memorias Conferencia Regional para América Latina de la IARTEM - Colombia. Pereira: Universidad Tecnológica de Pereira. 2016. 
VALARINI, D. Livros didáticos de ensino de arte: avaliação e análise crítica = Textbooks art of teaching: evaluation and review. 2016. 99 p. Dissertação (Mestrado) Universidade Estadual de Campinas, Instituto de Artes, Campinas, SP. Disponível em: <http://www.repositorio.unicamp.br/handle/REPOSIP/304762>. Acesso em: 30 ago. 2018.

VASCONCELLOS, S. T.; STORCK, K.; MOMOLI, D. B. Para onde caminha o ensino das Artes Visuais? Revista GEARTE, Porto Alegre, v. 5, n. 2, p. 245-258, maio/ago. 2018.

VIÑAO FRAGO, A. El libro de texto y las disciplinas escolares: una mirada a sus orígenes. In: ESCOLANO BENITO, A. (ed.). Currículum editado y sociedad del conocimiento. Texto, multimedialidad y cultura de la escuela. Valencia: Tirant lo Blanch, 2000.

i Doutora (2016) e Mestre (2007) em Educação pela Universidade Federal do Paraná/UFPR. Realizou estágio de doutoramento na Florida State University, no Departamento de Arte Educação, pelo programa CAPES/ FULBRIGHT. Possui Bacharelado no Curso Superior de Pintura (2000) pela EMBAP/PR e especialização (2004) em Ensino de Artes Visuais pela Universidade do Estado de Santa Catarina - UDESC. Atualmente é Coordenadora do Curso de Licenciatura em Artes Visuais da UNESPAR - Curitiba Campus II - FAP.

ii Doutor (2009) e Mestre em Educação (2000) pela Universidade Federal do Paraná. Professor e músico, possui graduação em Educação Artística - Habilitação em música pela Faculdade de Artes do Paraná (1997). Atualmente é professor associado da Universidade Federal do Paraná no Departamento de Teoria e Prática de Ensino, do Setor de Educação e do Programa de Pós-Graduação em Música da UFPR.

Como citar esse artigo:

TEUBER, Mauren; ROMANELLI, Guilherme Gabriel Ballande. O processo de escolha dos livros didáticos por professores de Arte: Mediações (in)imagináveis. Revista Digital do LAV, Santa Maria: UFSM, v. 13, n. 3, p. 114-137, set./dez. 2020. 